\title{
The self-care for people initiative: the outcome evaluation
}

\author{
Alan White ${ }^{1}$, Jane South ${ }^{1}$, Anne-Marie BagnalI ${ }^{2}$, Mark Forshaw ${ }^{3}$, Chris Spoor ${ }^{4}$, Paul Marchant ${ }^{5}$ and \\ Karl Witty \\ ${ }^{1}$ Professor, Institute for Health and Wellbeing, Leeds Metropolitan University, Leeds, UK \\ ${ }^{2}$ Senior Research Fellow, Institute for Health and Wellbeing, Leeds Metropolitan University, Leeds, UK \\ ${ }^{3}$ Principal Lecturer, Centre for Health Psychology, Faculty of Sciences, Staffordshire University, Staffordshire, UK \\ ${ }^{4}$ Principal Lecturer, School of Health and Wellbeing, Leeds Metropolitan University, Leeds, UK \\ ${ }^{5}$ Senior Lecturer, University Research Office, Leeds Metropolitan University, Leeds, UK \\ ${ }^{6}$ Research Officer, Institute for Health and Wellbeing, Leeds Metropolitan University, Leeds, UK
}

\begin{abstract}
Aim: To determine the effects of a community-based training programme in self-care on the lay population. Background: Self Care is recognised as being a cornerstone of the populations health, but to date there have been few large-scale studies of its effectiveness on the general public. This paper reports on an evaluation of a self-care skills training course delivered in small group sessions within workplace and parent and toddler group settings to a lay population. Methods: A quasi-experimental longitudinal study of 12-month duration was conducted in three intervention primary care trusts (PCTs) and two similar comparison PCTs in England. The sample comprised 1568 selfselecting participants: 868 received the intervention and 700 did not. Findings: No changes were seen in usage of General Practitioner services, the primary outcome, however, statistical analysis suggested that being in the intervention group may be associated with increased use of out-of-hours and secondary care services. At six months' follow-up small but statistically significant positive effects of being in the intervention group were seen on self-esteem, well-being and anxiety scores. At 12 months' follow-up small but statistically significant positive effects of being in the intervention group were also seen on recovery locus of control, health literacy and self-esteem scores, and on knowledge of adult cough. The clinical significance of these very small changes is unclear.

The training programme had a small but positive effect, which was still evident at 12 months, on individuals' knowledge and confidence levels with regard to managing their own health, but did not lead to reductions in health service use.
\end{abstract}

Keywords: community; health education; health literacy; health service use; intervention; self-care

Received 18 October 2011; revised 14 February 2012; accepted 26 February 2012; first published online 12 April 2012

\section{Introduction}

Self-care is vital in meeting our everyday health needs and in the day to day management of

Correspondence to: Professor Alan White, Faculty of Health and Wellbeing, Leeds Metropolitan University, Woodhouse Lane, Leeds LS2 8AF, UK. Email: a.white@leedsmet. ac.uk

(C) Cambridge University Press 2012 long-term conditions (Dean, 1981; Dean and Kickbush, 1995; Paterson et al., 2000; Bhuyan, 2004; Grandes et al., 2008; Skills for Health, 2008). The vision of a Fully Engaged society as proposed by Wanless (Department of Health (DoH), 2002b), added weight to this view and was consistent with the assertion as laid out in the National Health Service (NHS) Plan (DoH, 2000a) and elsewhere (DoH, 1999; 2000b; 2002a; 
2004a; 2004b; 2005a; 2005b; 2005c; 2007) that the frontline for healthcare is in the home, rather than traditionally defined healthcare settings. For a 'person-centred' health service to work, however, the population must be enabled to make the right choices with regards to health and which health services should be accessed. This fits with the definition of Self Care as proposed by the World Health Organisation as 'activities that individuals, families, and communities undertake with the intention of enhancing health, preventing disease, limiting illness, and restoring health' (WHO, 1983).

Most of the work that has been undertaken in the promotion of Self Care has, to date, been focused onto giving individuals with chronic problems such as diabetes, epilepsy, arthritis and asthma, knowledge to better understand and manage their health needs (for recent reviews of these programmes please refer to Berzins et al., 2009; Challis et al., 2011).

In 2005, as a response to the negotiation of the General Medical Services contract for general practitioners (GPs), the Working in Partnership Programme (WiPP) was established. The role of this body was to co-ordinate and facilitate the development of schemes to maximise the effective use of health services and to provide evidencebased alternatives to traditional general practice.

The remit given to WiPP was to enable the development of self-care into mainstream services and led to a number of pilot projects looking at how best to support individuals within their own communities. One of these was Self Care for People (SC4P), which had as a core component the development of a self-care skills training course to enable the general public to make changes leading to the adoption of more healthy lifestyles (Self Care Connect, 2009). The premise underlying the initiative was that, by increasing individuals' understanding of their own health and giving them both the skills to self-care and knowledge of what support is available within the community. The participants would be expected to then have a heightened sense of responsibility for their own health and that of others and be better able to proactively manage their health.

A key component of the thinking behind the initiative was the link between skills training and changing patterns of service use. The intention of the initiative was focused on well individuals such that they engaged in more protective health measures and had reduced reliance on clinical service usage. This can be modelled hypothetically:

Participation in skills training, etc. $\rightarrow$ increased knowledge and skills $\rightarrow$ confidence to undertake self-care $\rightarrow$ intention to self-care $\rightarrow$ changes in patterns of service use.

It was also identified that there were currently many support mechanisms and services within primary healthcare that had the potential to be an invaluable resource but individuals lacked awareness of their existence.

A sister programme (Self Care in Primary Care) focused on health professionals and involved the design of an educational programme for primary healthcare teams to promote self-care within general practice (White et al., 2009a). Although studies of self-care in specific populations, or in groups with particular health conditions, have reported impact on GP visits or other service use (e.g. Griffiths et al., 2000; Hammond and Freeman, 2001), to our knowledge no studies have addressed these outcomes in a more general population.

An evaluation of the SC4P initiative was undertaken, with the broad aim of assessing the impact on people who participated in this pilot initiative and on local health economies. The study also investigated the development and implementation of the SC4P initiative; this is discussed elsewhere (White et al., 2009b; South et al., 2010). The purpose of this paper is to present the findings from the outcome evaluation of the SC4P initiative.

\section{Study design and methods}

\section{Intervention}

The intervention was designed for delivery to the general population and piloted within three primary care trusts (PCTs). Self Care Support Coordinators in each PCT were responsible for organising and delivering the self-care skills course and creating local self-care networks. The course was composed of six blocks of activity that explored attitudes and personal skills in relation to healthcare and self-care (WiPP, 2006):

- Block 1: exploring attitudes to health- and selfcare.

- Block 2: understanding the process of change and how to change health behaviours. 
- Block 3: focusing on developing confidence and self-esteem.

- Block 4: exploring psychological aspects of health and well-being including the management of stress and anxiety.

- Block 5: healthy eating and changing eating habits.

- Block 6: the benefits of exercise and self-care of minor conditions.

The course was delivered in small group sessions in non-clinical settings with six three hour sessions provided over a three to six-week period. A handbook containing reference material and follow-up exercises accompanied the course. During the period of the study, courses were held in both workplaces and communitybased services used by parents with young children (referred to as parent groups in this paper), with these locations specifically targeted to ensure the sample included both men and women. Despite the self-care support coordinators being given local discretion in implementation, the findings show little divergence between PCTs, despite the different local contexts with regard to the fidelity of implementation of the programme (South et al., 2010). Unfortunately the monitoring data from local implementation was not robust enough to be included in our overall analysis or to allow us to draw any firm conclusions.

This was a policy-driven initiative, which did attempt to modify individual behaviour and to link that to drivers around service use. This influenced our choice of outcome measures. The initiative was not underpinned by any particular theoretical model of behaviour change.

\section{Study design}

The quasi-experimental design examined participant level data in three intervention PCT areas over a 12-month period before and after the intervention. Data was also gathered on individuals in two further comparison areas with a demographic profile similar to two of the intervention areas (Nutbeam et al., 1993; Potvin and Richard, 2001). Randomisation was not feasible as individuals self-selected to undertake the selfcare skills training course in the intervention areas. This was a pilot intervention and it was felt that using a range of data sources and validated measures would be more likely to capture possible effects and would strengthen the evidence by triangulation (Green and South, 2006). Three methods were used to collect data on study participants:

1. Routinely collected individual level general practice and secondary service utilisation data.

2. Questionnaires administered to all participants at baseline, 6 and 12 months.

3. Qualitative, semi-structured interviews conducted with a sub sample of participants receiving the intervention at baseline, 6 and 12 months (reported elsewhere).

\section{Outcome measures}

We hypothesised that participation in the selfcare skills course would result in the intermediate outcomes of increased self-care knowledge and skills, increased confidence to undertake self-care, and greater intention to self-care. The primary outcome was a change in number of GP consultations between baseline and follow-up. Routinely collected data on participants' primary care service use were obtained from participants' general practices. The following data were collected for each participant: consultations with a GP (whether in person or by telephone); consultations with other primary healthcare professionals (PHCPs, in person or by telephone); and use of the out of hours service.

In case increasing peoples' awareness of services affected their wider health service usage, data on secondary care service use by individual study participants were obtained centrally from participating PCTs. The following variables were collected: visits to an Accident and Emergency department; outpatient consultations; and hospital admissions.

Data on study participants' use of the NHS Direct telephone service was collected centrally from NHS Direct.

Standardised psychological outcome measures were selected to monitor aspects of the psyche potentially related to intervention effectiveness. They allowed a multivariate exploration of changes in self-esteem, well-being, anxiety and changes in beliefs about recovery from illness in respect of personal control and produce a holistic picture of changes to individuals' health-related outlook.

Structured questionnaires were administered to all participants at baseline, 6 and 12 months. 
The questionnaires incorporated items from standardised psychometric scales to measure: anxiety (Hospital Anxiety and Depression Scale; Zigmond and Snaith, 1983), perceived stress (Short Perceived Stress Scale-4; Cohen and Williamson, 1988), self-esteem (Rosenberg Self-Esteem scale; Rosenberg, 1989), recovery locus of control (Recovery Locus of Control scale; Partridge and Johnston, 1989) and subjective well-being (Subjective Well-being Scale; Diener et al., 1989).

There were also questions on demographic information, health status, social support and knowledge of minor ailments, self-reported patterns of service use; health literacy with regard to decision making about when to use services, intention to use primary care services, exposure to other self-care initiatives and resources.

\section{Sample}

The sample was drawn from people attending self-care skills training courses, which were held in parent and child groups and in workplaces within intervention PCTs. Recruitment to the control PCTs was through direct contact and appeal for volunteers through the same routes as used for the intervention cohort, parent and toddler groups and the workplace. Course participants volunteered to attend the course, and were not selected on the basis of their health or any other criteria. Course participants were then invited to take part in the evaluation, either at or before the first session, and given recruitment packs containing information about the study, baseline questionnaires and consent forms. All those involved gave written consent to take part in the study.

The sample size calculation used the primary outcome of change in GP consultation rate between the last six months of the study and the six months before entry into the study. An estimated annual GP visit rate of 4 in this population (Badhavi et al., 2006) and an expected effect size of $20 \%$ gave an approximate required sample size of 550 in each group at the end of the 12-month follow-up for a statistical power of $90 \%$ and a critical significance level of 0.05 (assuming the effect of clustering to be negligibly small). Recruitment targets were set at 864 in each group, which included allowance for a $20 \%$ attrition rate at both 6- and 12-month time points.

\section{Analysis}

Routine data on individual participants' service use was collected for two six-month periods. The baseline period for each participant referred to the six months prior to the first day of the month in which they joined the study. The follow-up period referred to the same six-month period, one calendar year later, to account for seasonal trends.

Numbers of consultations with GPs, and separately for other PHCPs, were totalled for each participant within the baseline and follow-up periods. For simple exploration the change in number of consultations between the baseline and follow-up six-month period was calculated for each participant. Means and $\sim 95 \%$ confidence intervals for these differences were then calculated by group (intervention versus comparison) and by PCT and these were examined visually by plotting them against a reference line representing no change (SPSS 16.0).

The analysis was developed by running a generalised linear model (GLZM) of the number of consultations in the follow-up period, taking into account baseline consultations, gender and setting (workplace or parent group), as well as intervention or comparison group, using negative binomial distribution and a logarithmic link function, applied to the count variables (for sampling zeros in the baseline count, $\frac{1}{2}$ was added before logging).

For all other routine data outcomes (out of hours use, A\&E visits, NHS Direct phone-line contacts, outpatient visits and hospital admission), the number of people experiencing events was too low to use count data in the same way as above. Instead, a GLZM (SPSS 16.0) with logistic link was used to compare the proportions of people having contact and not having contact with services in follow-up periods controlling for setting, gender and baseline contact.

Total scores on psychometric scales were calculated for each participant, and the mean and standard deviation in intervention and comparison groups at each time point were determined. Questionnaires with partial and non-responses to single or multiple items in the psychometric scales were excluded from the analysis for that scale. Separate linear regression analysis was undertaken for each scale (SPSS 16.0) with the dependent variables being scores at 6 and 12 months, and predictor variables being scores at baseline, gender and setting (workplace or parent group), as well as 
group (intervention or comparison). The findings from these were compared with those from a multivariate linear model run with the same variables as above at both outcome time points.

Responses to ordinal scales on knowledge of minor ailments, perceived health status and social support were compared between groups at 6 and 12 months' follow-up using generalised linear cumulative logistic models, using the same predictor variables.

A sensitivity analysis was run using the last observation carried forward for participants with missing outcomes.

\section{Results}

\section{Participants}

1568 participants were included in the study (see Table 1 for demographics of sample).

Sixty-five participants withdrew from the study or were lost to follow-up. A further 545 participants could not be included in the analysis of the primary outcome, either because they did not provide GP details (192 participants) or because their GP Practice was outside the participating PCT area or would not provide routine service use data (353 participants). This left 958 participants with data available for the primary outcome: 544 in the intervention group and 414 in the comparison group. It is important to note that $45 \%$ of all participants considered themselves to have a health condition $(45 \%$ in the comparison group and $46 \%$ in the intervention group) - this is high compared with 2001 Census results $(18.2 \%$ in England and Wales reported limiting long-term illness while $9.2 \%$ said their general health was 'not good').

Data on use of secondary services were obtained directly from participating PCTs, but were not available for one of the two comparison PCTs (total $n=808$ ). See Figure 1 for a diagram of participant flow.

657 questionnaires were returned at six months and 622 at twelve months. The response rate to the final questionnaire was $39 \%$.

\section{Routine data}

The average number of contacts with services during baseline and follow-up periods in intervention and comparison groups are presented in Table 2, which indicates the skew in the data. For less common outcomes, numbers of people having some contact with services during baseline and follow-up periods in intervention and comparison groups are presented in Table 3.

The negative binomial GLZM found that the intervention did not make a detectable difference to the number of consultations with GPs or other PHCPs in the follow-up period, taking into account the number of baseline consultations as appropriate (expected number of GP consultations for a person in the intervention group is 1.15 times that of their counterpart in the comparison group, $95 \% \mathrm{CI}$ : $0.96,1.36, P=0.126$; expected number of PHCP consultations for a person in the intervention group is 1.17 times that of their counterpart in the comparison group, 95\% CI: $0.93,1.46, P=0.182$ ). In both groups, males were statistically significantly less likely than females to consult GPs or other PHCPs in the follow-up period for a given level of baseline consultations (expected number of GP

Table 1 Participant characteristics at baseline

\begin{tabular}{lllr}
\hline Category of participants & Intervention, $n(\%)$ & Comparison, $n(\%)$ & Total, $n(\%)$ \\
\hline Total & 868 & 700 & 1568 \\
Age (mean) & 40.1 & 36.9 & 38.6 \\
Male & $202(23 \%)$ & $306(44 \%)$ & $508(32 \%)$ \\
White & $727(84 \%)$ & $649(93 \%)$ & $1376(87 \%)$ \\
Black & $19(2.1 \%)$ & $10(1.4 \%)$ & $29(1.8 \%)$ \\
Asian & $95(11 \%)$ & $31(4.4 \%)$ & $126(7.9 \%)$ \\
No qualifications & $116(13 \%)$ & $70(10 \%)$ & $186(12 \%)$ \\
Degree or equivalent & $173(20 \%)$ & $189(27 \%)$ & $362(23 \%)$ \\
Recruited from workplace & $599(69 \%)$ & $397(57 \%)$ & $996(63 \%)$ \\
Live with family & $691(80 \%)$ & $591(84 \%)$ & $1282(82 \%)$ \\
Live alone & $152(18 \%)$ & $86(12 \%)$ & $238(15 \%)$ \\
Health conditions & $400(46 \%)$ & $313(45 \%)$ & $713(45 \%)$ \\
\hline
\end{tabular}

Primary Health Care Research \& Development 2012; 13: 382-394 
Flow of participants through study

\section{Intervention}
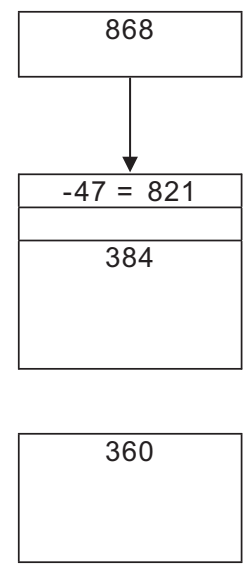

$821-277$

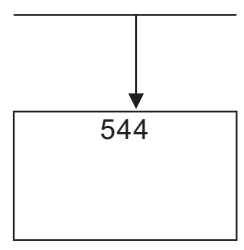

$821-277$

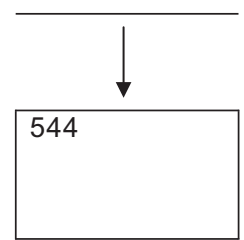

\section{Comparison}
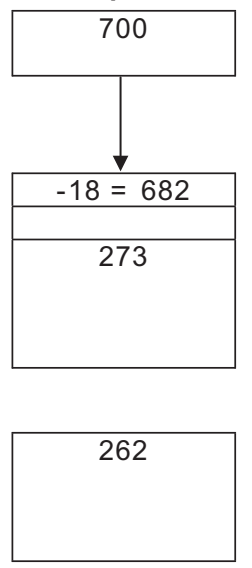

$682-268$

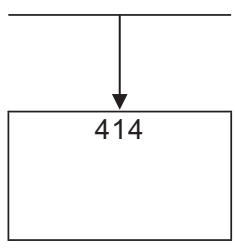

$682-417$

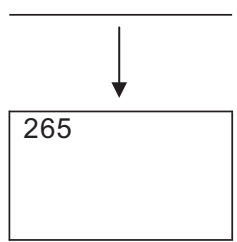

1568

Recruited

65 withdrew

657 questionnaires returned at 6 months

622 questionnaires returned at 12 months

545 had no Practice-level routine data

958 included in routine data on primary service use

695 had no PCT-level routine data

808 included in routine data on secondary service use

Figure 1 Flow of participants through study. PCT = primary care trust

Table 2 Number of consultations over baseline and follow-up six-month periods: mean (SD)

\begin{tabular}{|c|c|c|c|c|}
\hline \multirow[t]{2}{*}{ Consultation rate } & \multicolumn{2}{|c|}{ Intervention } & \multicolumn{2}{|c|}{ Comparison } \\
\hline & Baseline & Follow-up & Baseline & Follow-up \\
\hline GP & $1.84(2.57)$ & $2.04(2.62)$ & $1.65(2.56)$ & $1.77(2.35)$ \\
\hline Other PHCP & $0.72(1.27)$ & $0.86(1.62)$ & $0.6(1.23)$ & $0.64(1.26)$ \\
\hline Out of hours & $0.06(0.42)$ & $0.10(0.55)$ & $0.02(0.14)$ & $0.03(0.22)$ \\
\hline$A \& E$ & $0.03(0.20)$ & $0.06(0.26)$ & $0.05(0.29)$ & $0.04(0.19)$ \\
\hline NHS Direct & $0.06(0.29)$ & $0.09(0.34)$ & $0.06(0.26)$ & $0.09(0.38)$ \\
\hline Outpatient visits & $0.29(0.89)$ & $0.40(1.17)$ & $0.10(0.60)$ & $0.23(1.51)$ \\
\hline Hospital admissions & $0.06(0.27)$ & $0.13(0.63)$ & $0.03(0.30)$ & $0.03(0.26)$ \\
\hline
\end{tabular}

$\mathrm{GP}=$ general practitioner; $\mathrm{PHCP}=$ primary healthcare professional; NHS = National Health Service.

Primary Health Care Research \& Development 2012; 13: 382-394 
Table 3 Numbers having contact with services (for outcomes with low event rates): $n / N$

\begin{tabular}{|c|c|c|c|c|}
\hline & \multicolumn{2}{|c|}{ Intervention } & \multicolumn{2}{|c|}{ Comparison } \\
\hline & Baseline & Follow-up & Baseline & Follow-up \\
\hline Out of hours & $18 / 543$ & $33 / 543$ & $8 / 415$ & $11 / 415$ \\
\hline$A \& E$ & $17 / 543$ & $26 / 543$ & $15 / 415$ & $15 / 415$ \\
\hline NHS Direct & $57 / 821$ & $64 / 821$ & $33 / 682$ & $35 / 682$ \\
\hline Outpatients & $78 / 543$ & $96 / 543$ & $21 / 415$ & 23/415 \\
\hline Hospital admission & $28 / 543$ & $36 / 543$ & $8 / 415$ & $8 / 415$ \\
\hline
\end{tabular}

NHS $=$ National Health Service.

Table 4 Scale scores at baseline, 6 and 12 months

\begin{tabular}{llcr}
\hline Scale & Time point & Intervention & Comparison \\
\hline Anxiety & Baseline & $8.05(4.10) 841$ & $6.56(3.85) 689$ \\
& 6 months & $6.99(3.83) 381$ & $6.78(3.97) 267$ \\
Stress & 12 months & $6.85(3.98) 334$ & $6.36(3.87) 249$ \\
& Baseline & $6.49(3.15) 848$ & $5.64(3.02) 684$ \\
Self-esteem & 6 months & $5.84(3.12) 373$ & $5.26(3.01) 269$ \\
& 12 months & $5.45(3.07) 339$ & $5.34(3.28) 254$ \\
& Baseline & $20.82(4.75) 818$ & $19.47(4.30) 665$ \\
Well-being & 6 months & $19.23(4.75) 370$ & $19.14(4.45) 266$ \\
& 12 months & $18.94(4.87) 333$ & $19.37(4.50) 247$ \\
& Baseline & $21.43(6.66) 844$ & $23.65(6.32) 689$ \\
Locus of control & 6 months & $22.73(6.69) 377$ & $23.57(6.43) 269$ \\
& 12 months & $22.45(7.04) 339$ & $24.22(6.20) 253$ \\
Health literacy & Baseline & $34.55(4.17) 833$ & $34.20(3.84) 682$ \\
& 6 months & $34.95(3.84) 372$ & $34.35(3.70) 267$ \\
& 12 months & $35.44(4.08) 334$ & $34.60(3.77) 252$ \\
& Baseline & $11.15(1.91) 855$ & $11.30(1.80) 693$ \\
& 6 months & $11.75(1.76) 377$ & $11.74(1.60) 269$ \\
& 12 months & $11.92(1.73) 342$ & $11.57(1.66) 254$ \\
\hline
\end{tabular}

All values reported as mean (SD) $n$.

consultations for a male participant is 0.75 times that of their female counterpart, 95\% CI: 0.61 , $0.92, P=0.005$; expected number of PHCP consultations for a male participant is 0.55 times that of their female counterpart, 95\% CI: $0.42,0.73$ consultations, $P<0.001)$.

The logistic regression GLZM found the proportion of people using services in the follow-up period was statistically significantly increased in the intervention group compared with the comparison group for out of hours services (odds ratio 2.26, 95\% CI: $1.10,4.92, P=0.031$ ), outpatient visits (odds ratio $3.11,95 \% \mathrm{CI}: 1.83,5.45, P<0.001$ ) and hospital admissions (odds ratio $3.90,95 \% \mathrm{CI}$ : $1.80,9.42, P=0.001)$.
No statistically significant changes were seen in use of $A \& E$ services comparing the intervention group to comparison (odds ratio 1.64, 95\% CI: $0.84,3.32, P=0.157$ ) or of NHS Direct (odds ratio $1.36,95 \% \mathrm{CI}: 0.88,2.11, P=0.169)$. In both groups, males were statistically significantly less likely to use NHS Direct than females in the follow-up period (odds ratio $0.49,95 \%$ CI: 0.28 , $0.82, P=0.009)$.

\section{Questionnaire data}

\section{Psychometric scales}

Table 4 presents average scores in the intervention and comparison groups at baseline and 
follow-up for published psychometric scales and for a health literacy scale developed by the research team and relating to decision making around service use. Table 5 presents average changes in scores from baseline in each group at 6 and 12 months' follow-up.

The results of the separate linear regressions (Table 6) showed statistically significant but small effects in favour of the intervention on anxiety $(-0.59$ points, 95\% CI: $-1.08,-0.11)$, self-esteem $(-0.75$ points, $95 \%$ CI: $-1.32,-0.18)$ and well-being ( 0.99 points, $95 \%$ CI: $0.16,1.81)$ at six months, and on health literacy ( 0.31 points, 95\% CI: $0.05,0.57)$, recovery locus of control $(0.88$ points, $95 \% \mathrm{CI}: 0.27,1.49)$ and self-esteem $(-0.99$ points, $95 \% \mathrm{CI}:-1.60,-0.37)$ at 12 months.

The results of the multivariate model (White et al., 2009b) were similar to those of the separate linear regressions, except that there was no longer a statistically significant positive effect of the intervention on health literacy at the 12-month follow-up, but there was a statistically significant

Table 5 Change in scores from baseline

\begin{tabular}{llrr}
\hline Scale & Time point & Intervention & \multicolumn{1}{c}{ Comparison } \\
\hline Anxiety & 6 months & $-0.73(3.29) 371$ & $0.10(2.76) 263$ \\
& 12 months & $-1.02(3.43) 326$ & $-0.25(2.93) 244$ \\
Stress & 6 months & $-0.17(2.75) 372$ & $-0.09(2.09) 263$ \\
& 12 months & $-0.68(2.94) 337$ & $-0.10(2.91) 247$ \\
Self-esteem & 6 months & $-0.87(3.61) 362$ & $-0.02(3.35) 260$ \\
& 12 months & $-1.36(4.09) 322$ & $-0.24(3.07) 239$ \\
Locus of control & 6 months & $-0.02(4.40) 363$ & $-0.15(4.01) 266$ \\
& 12 months & $0.72(4.09) 325$ & $0.36(3.73) 251$ \\
Well-being & 6 months & $0.87(5.22) 371$ & $-0.64(4.95) 268$ \\
& 12 months & $1.13(5.48) 333$ & $0.41(5.16) 251$ \\
Health literacy & 6 months & $0.41(1.81) 377$ & $0.19(1.69) 269$ \\
& 12 months & $0.57(1.77) 341$ & $0.10(1.84) 253$ \\
\hline
\end{tabular}

All values reported as mean (SD) $n$.

Table 6 Summary of single-regression effects of being in intervention group on psychometric and other scale scores

\begin{tabular}{|c|c|c|c|c|c|c|c|}
\hline \multirow[t]{2}{*}{ Scale } & \multirow[t]{2}{*}{ Time point } & \multirow[t]{2}{*}{$n$} & \multirow[t]{2}{*}{$B$} & \multirow[t]{2}{*}{ Standard error } & \multirow[t]{2}{*}{ Significance } & \multicolumn{2}{|c|}{$95 \% \mathrm{Cl}$ for $B$} \\
\hline & & & & & & Lower bound & Upper bound \\
\hline Anxiety & $\begin{array}{l}6 \text { months } \\
12 \text { months }\end{array}$ & $\begin{array}{l}597 \\
537\end{array}$ & $\begin{array}{r}-0.593 \\
0.314\end{array}$ & $\begin{array}{l}0.249 \\
0.267\end{array}$ & $\begin{array}{l}0.017 \\
0.240\end{array}$ & $\begin{array}{l}-1.082 \\
-0.839\end{array}$ & $\begin{array}{r}-0.105 \\
0.210\end{array}$ \\
\hline Stress & $\begin{array}{l}6 \text { months } \\
12 \text { months }\end{array}$ & $\begin{array}{l}599 \\
551\end{array}$ & $\begin{array}{r}0.067 \\
-0.381\end{array}$ & $\begin{array}{l}0.228 \\
0.234\end{array}$ & $\begin{array}{l}0.769 \\
0.104\end{array}$ & $\begin{array}{l}-0.381 \\
-0.841\end{array}$ & $\begin{array}{l}0.515 \\
0.078\end{array}$ \\
\hline Health literacy & $\begin{array}{l}6 \text { months } \\
12 \text { months }\end{array}$ & $\begin{array}{l}609 \\
562\end{array}$ & $\begin{array}{l}0.130 \\
0.310\end{array}$ & $\begin{array}{l}0.127 \\
0.133\end{array}$ & $\begin{array}{l}0.307 \\
0.020\end{array}$ & $\begin{array}{r}-0.120 \\
0.049\end{array}$ & $\begin{array}{l}0.379 \\
0.572\end{array}$ \\
\hline Locus of control & $\begin{array}{l}6 \text { months } \\
12 \text { months }\end{array}$ & $\begin{array}{l}593 \\
544\end{array}$ & $\begin{array}{l}0.507 \\
0.877\end{array}$ & $\begin{array}{l}0.300 \\
0.310\end{array}$ & $\begin{array}{l}0.092 \\
0.005\end{array}$ & $\begin{array}{r}-0.082 \\
0.268\end{array}$ & $\begin{array}{l}1.096 \\
1.485\end{array}$ \\
\hline Well-being & $\begin{array}{l}6 \text { months } \\
12 \text { months }\end{array}$ & $\begin{array}{l}605 \\
553\end{array}$ & $\begin{array}{r}0.986 \\
-0.033\end{array}$ & $\begin{array}{l}0.419 \\
0.451\end{array}$ & $\begin{array}{l}0.019 \\
0.941\end{array}$ & $\begin{array}{r}0.164 \\
-0.919\end{array}$ & $\begin{array}{l}1.808 \\
0.852\end{array}$ \\
\hline Self-esteem & $\begin{array}{l}6 \text { months } \\
12 \text { months }\end{array}$ & $\begin{array}{l}587 \\
534\end{array}$ & $\begin{array}{l}-0.751 \\
-0.986\end{array}$ & $\begin{array}{l}0.291 \\
0.314\end{array}$ & $\begin{array}{l}0.010 \\
0.002\end{array}$ & $\begin{array}{l}-1.322 \\
-1.603\end{array}$ & $\begin{array}{l}-0.179 \\
-0.368\end{array}$ \\
\hline
\end{tabular}


positive effect of the intervention on recovery locus of control at six months' follow-up.

The separate regression models were able to include more participants in the analyses; however, in the multivariate model significant interactions were seen between several of the scales, suggesting that the measures are not entirely independent of each other.

The last observation carried forward analysis made no substantial difference to the findings (White et al., 2009b). A further multilevel analysis (MLWin 2.0) taking into account clustering of individuals within the five PCTs also made no substantial difference.

\section{Ordinal outcomes}

A cumulative logistic GLZM found no statistically significant effect of being in the intervention group on perceived health status, levels of social support, or knowledge about children's cough, back pain or crying in babies at 6 and 12 months' follow-up, controlling for baseline, gender and setting. Statistically significant positive effects of being in the intervention group were seen at six months in intention to use GP services less for minor ailments and, at 12 months, in knowledge about back pain.

\section{Intention to use services}

Participants were given a list of services and asked which they intended to use in the next six months. Their responses indicated some differences between intervention and comparison groups. At baseline, more than $90 \%$ of all participants stated an intention to use the family doctor, and more than $80 \%$ to use the pharmacist or family for support. At the 12-month follow-up, intention to use support from friends, hospital, the library, occupational health, social workers and Thomson local had increased in the intervention group but not the comparison group. Intention to use support from health visitors and midwives had decreased in the comparison group but not in the intervention group.

\section{Discussion}

The analysis of the routinely collected data demonstrated that being in the intervention group was not associated with a decrease in use of primary care services (the primary study outcome). An association was seen between being in the intervention group and increased use of out of hours and secondary healthcare services; this increase was an unexpected finding and though the exact mechanism was not explored in this study it could warrant further investigation.

Both analysis models found statistically significant but small effects in favour of the intervention in anxiety, self-esteem and well-being at six months and in recovery locus of control and self-esteem at 12 months. These effects were very small; the maximum plausible change on any scale being less than two points, and their potential clinical significance is unclear.

\section{Strengths and limitations of study}

This study is the first large scale evaluation of a self-care training package aimed at the general public to triangulate longitudinal routine data on actual health service usage, questionnaire responses and interview data.

Though the included data is accurate, the large amount of missing routine data, particularly from the comparison PCTs, means that these results should be treated with caution.

The response rate for follow-up questionnaires was also low. Recruitment rates were high in the intervention group where there was support for completion of the questionnaire, but reliance on postal questionnaires for follow-up may have proved problematic for those with literacy or language issues. This may have affected representativeness in the follow-up sample. It is recognised that along with missingness comes the potential for bias. The high dropout and hence large amount of missing data are likely to lead to unknown biases being present in the final data set.

Potential for selection bias arises from having practitioners who are involved in the initiative recruiting for the research study. Even with protocols and standardised information, certain types of people, directly or indirectly, may have received more encouragement than others to take part. Recruitment for the comparison group was undertaken by the University team at settings in comparison PCT areas with similar demographic profiles. There was potential selection bias here too in identifying settings and recruiting participants and this may have implications for the applicability of the study findings. On the other 
hand, the intervention was run in natural community settings and recruitment methods reflected the application of community-based health promotion approaches, such as using existing networks (White et al., 2009b).

There was a higher number of women, people from black and minority ethnic groups and people recruited from the workplace in the intervention than the comparison group; also higher levels of stress and anxiety, with less perceived social support at baseline, which may be indicative of greater need in the intervention group, and also greater reach of the intervention, as results from the process evaluation would indicate (White et al., 2009b). This may, however, have implications for representativeness and generalisability.

Participants were grouped and followed up with respect to 'intention to treat' though, as in any delivery of a complex intervention, not all participants will have completed all the components of the training programme. The process evaluation undertaken did, however, show that that there was a high level of engagement with the programme such that it is most likely that the majority did complete the course (White et al., 2009b).

It is remarkable that for an intervention aimed at the general population, $45 \%$ of the sample reported that they had a health condition (in the 2001 census $18.2 \%$ in England and Wales reported limiting longterm illness while $9.2 \%$ said their general health was 'not good'). Involvement in the programme was on a self-selection basis and it may be that this form of health programme appeals more to those with existing health worries or actual conditions. It is noticeable that from analysis of the routine data the actual usage of health services was not high, with both the comparison group and intervention having around a mean of two visits over the 6-month baseline and follow-up periods. This could suggest that the health conditions were stable or not sufficiently problematic to warrant health service usage or it could be an indicator of patient delay in seeking help (White and Banks, 2009).

\section{Findings in relation to other studies}

The focus of the majority of the studies relating to self-care has been on long-term conditions, with the emphasis more on self-management (Bury et al., 2005). A recent overview of this evidence base for the DoH (2007) suggests that targeted programmes aimed at improving the ability of patients to deal with their day to day health needs can result in beneficial health outcomes for people and more appropriate use of health and social care services.

Though some individual studies (Choy et al., 1999) of self-care interventions have shown that there is a reduction in utilisation of healthcare services, this does not appear to be a wide spread occurrence. The findings from our study are similar to those from the national evaluation of the Expert Patient Programme (EPP; National Primary Care Research and Development Centre (NPCRDC), 2006) in that they found no impact on routine health service use for people with long-term conditions attending a short course on self-care skills. In that study, however, they did find that being a participant on the course led to moderate gains in self-efficacy, and small gains in energy, quality of life, psychological well-being and partnerships with doctors.

The authors of the EPP report suggested three possible reasons for the lack of change in service use: established consulting routines of individuals; organisational influences on service use, for example, requirements to attend for tests, monitoring and repeat prescriptions; and EPP course delivery being separate from advice and actions of professionals working in the health service. These factors may also be at play with the participants on this current study; even though they were not selected on the basis of having a longterm condition or frequent service use, they may already have had well-established help seeking behaviours (White et al., 2009b).

The EPP evaluation (NPCRDC, 2006) reported no change in outpatient attendances; however, there was a small but statistically significant increase in this study. The reasons for this increase are not clear, but it is worth noting that outpatient attendances are largely determined by health professionals and therefore may not be influenced by the participants self-care ability. The participants on this study were not selected for their previous health history and this may also have had a bearing on their health experiences throughout the study period.

There have been relatively few studies of interventions aimed at the general public in a similar way to the SC4P initiative. The limited published work that exists tends to emanate from America, where the financial incentives to self-care are much greater than in the United Kingdom. One such 
study (Powell et al., 1997) did show a 24\% decrease in employee healthcare costs after one year, due to reduced healthcare provider and emergency department visits. There have been others that have reported effectiveness in reducing health service usage (Steinweg et al., 1998; Hibbard et al., 2001) but these studies have tended to rely on selfreporting of help-seeking behaviour.

The 'Joining up Self Care' (PAGB/WiPP, 2006) study, which was based on an analysis of one PCT undertaking a number of different self-care initiatives, showed an increase in confidence of the participants to manage their own health needs in a similar way to the findings of this study. There was no measurement of actual health service usage, but the suggestion was that this improvement in confidence would result in changes.

It has to be noted that there are components relating to the introduction of self-care that have previously been seen to be problematic. Segall and Goldstein (1989) point out the dangers of allowing self-care to become overmedicalised. There is also a need to avoid self-care practices leading to patients becoming overly focused on ill health (Carr, 1990) or feeling a sense of undue blame for their ill health (Segall and Goldstein, 1989). These effects were not noted in either the follow-up questionnaire or interview data, but providers of self-care programmes should be aware of these potentially negative effects.

The increases in self-esteem and internal locus of control over the course of the intervention were as predicted, and concordant with increases in health literacy attributable to the intervention. Although it is not possible to comment unequivocally on causality, a tentative model in line with our original hypotheses can be posited. As health literacy increases, so would the perception among participants that they possess the tools to take greater responsibility for themselves and their own healthcare. This in itself could lead to changes in locus of control in the direction of internality. Furthermore, the combination of increased knowledge (known to psychologists as 'instrumental support'; Steptoe and Ayers, 2004) and an elevated level of internal locus of control would conceivably impact on self-esteem in a positive way. This in itself does not seem to have had a significant effect on service usage levels, perhaps indicating that the psychological changes attributable to the intervention may require longer time for 'bedding in' before they are detectable behaviourally.

A further explanation for the lack of change in health service use has been developed by Kennedy et al. (2007) who note that there is a complex interplay of factors involved in patient interactions with their health centre and if change is to be seen there needs to be a whole systems perspective taken with action at the patient, the professional and structural levels. In this current study, we can see that the package had an expected effect on the participants, but it could be argued that by not addressing the structural and professional boundaries it was not as effective as it might have been. A sister initiative aimed at changing the culture within general practice did demonstrate that this is a complex undertaking and not amenable to an 'easy fix' (White et al., 2009a) A further factor involved could be that attitudes to roles of the GP and other healthcare professionals have built up over 60 years such that it may be over optimistic to expect rapid change that is out of context with societal views.

\section{Conclusion}

With the emergence of 'Self Care' within a broad range of policy initiatives (DoH, 1999; 2000a; 2000b; 2004a; 2005c), this was an important attempt by the DoH to explore the impact of training on the general public. Though the primary outcome measure of a reduction in health service usage was not evident in the medium term, there were small but positive improvements in the participants knowledge and the confidence to self-care that were still evident 12 months later. If people are to be expected to take on a greater responsibility for their health then the provision of self-care training may offer some benefits.

It would seem sensible that studies of similar initiatives should include a longer follow-up period to determine whether the changes noted in our separate qualitative interviews (White et al., 2009b) are maintained and whether health service use behaviour does alter in line with patient intentions.

\section{Acknowledgement}

This study was approved by the ethics committee at Leeds West. 


\section{References}

Badhavi, M., Osborne, V., Yar, M. and Meltzer, H. 2006: Focus on Health. National Statistics 2006 Edition. Houndmills, Basingstoke Palgrave Macmillian.

Berzins, K., Reilly, S., Abell, J., Hughes, J. and Challis, D. 2009: UK self-care support initiatives for older patients with long-term conditions: a review. Chronic Illness 5, $56-72$.

Bhuyan, K.K. 2004: Health promotion through self care and community participation: elements of a proposed programme in the developing countries. BMC Public Health 4, 1471-2458.

Bury, M., Newbould, J. and Taylor, D.A. 2005: Rapid review of the current state of knowledge regarding lay-lead self management of chronic illness: evidence review. London: NICE, ISBN: 1-84629-142-9.

Carr, P. 1990: When over compliance means trouble. Nursing 90, 65-66.

Challis, D., Hughes, J., Berzins, K., Reilly, S., Abell, J., Stewart, K. and Bowns, I. 2011: Implementation of case management in long-term conditions in England: survey and case studies. Journal of Health Services Research \& Policy 16, Suppl 1, 8-13.

Choy, L., Ko, T., Ho, L., Leung, C. and Lai, C.K.W. 1999: Evaluation of the efficacy of a hospital-based asthma education programme in patients of low socioeconomic status in Hong Kong. Clinical \& Experimental Allergy 29, 84-90.

Cohen, S. and Williamson, G.M. 1988: Perceived stress in a probability sample of the United States. In Oskamp, A., Spacapan, A., editor, The social psychology of health. California: Sage, 31-67.

Dean, K. 1981: Self-care responses to illness: a selected review. Social Science \& Medicine 15A, 673-87.

Dean, K. and Kickbush, I. 1995: Health related behavior in health promotion: utilizing the concept of self care. Health Promotion International 10, 35-40.

Department of Health (DoH) 1999: Saving lives: our healthier nation. London: DH Publications.

DoH. 2000a: The NHS Plan: a plan for investment, a plan for reform. London: DH Publications.

DoH. 2000b: Pharmacy in the future: implementing the NHS Plan. London: DH Publications.

DoH. 2002a: Delivering the NHS Plan: next steps on investment; next steps on reform. London: DH Publications.

DoH. 2002b: Securing our future health: taking a long term view - the Wanless Report. London: DH Publications.

DoH. 2004a: National standards, local action: health and social care standards and planning framework. London: DH Publications.

DoH. 2004b: NHS improvement plan. London: DH Publications.

DoH. 2005a: Public attitudes to self care - baseline survey, February 2005. London: DH Publications.
DoH. 2005b: Self care - a real choice, self care support - a practical option. London: DH Publications.

DoH. 2005c: Self care support: baseline study of activity and development in self care support in PCT and other provider agencies. London: DH Publications.

DoH. 2007: Research evidence on the effectiveness of self care support (work in progress 2005-2007). London: DoH. Avilable at http://www.dh.gov.uk/en/Publicationsandstatistics/ Publications/PublicationsPolicyAndGuidance/DH_080689

Diener, E., Emmons, R.A., Larson, R.J. and Griffin, S. 1989: The satisfaction with life scale. Journal of Personality Assessment 49, 71-76.

Grandes, G., Sanchez, A., Cortada, J.M., Balague, L., Calderon, C., Arrazola, A., Vergara, I., Millan, E. and the 'Prescribe Vida Saludable' group. 2008: Is integration of healthy lifestyle promotion into primary care feasible? Discussion and consensus sessions between clinicians and researchers. BMC Health Services Research 10, 1472-6963.

Green, J. and South, J. 2006: Evaluation. Berkshire: Open University Press.

Griffiths, T.L., Burr, M.L., Campbell, I.A., Lewis-Jenkins, V., Mullins, J., Shiels, K., Turner-Lawlor, P.J., Payne, N., Newcombe, R.G., Lonescu, A.A., Thomas, J. and Tunbridge, J. 2000: Results at 1 year of outpatient multidisciplinary pulmonary rehabilitation: a randomised controlled trial. Lancet 8, 355(9211), 1280.

Hammond, A. and Freeman, K. 2001: One year outcomes of a randomized controlled trial of an educational behavioural joint protection programme for people with rheumatoid arthritis. Rheumatology 40, 1044-051.

Hibbard, J.H., Geenlick, M., Jimison, H., Capizzi, J. and Kunkel, L. 2001: The Impact of a community-wide self-care information project on self-care and medical care utilization. Evaluation \& the Health Professions 24, 404-23.

Kennedy, A., Rogers, A. and Bower, P. 2007: Support for self care for patients with chronic disease. BMJ 335, 968-70.

National Primary Care Research and Development Centre (NPCRDC) National Evaluation Team. 2006: Final Report: The National Evaluation of the Pilot Phase of the Expert Patient Programme. Manchester: National Primary Care Research and Development Centre, University of Manchester.

Nutbeam, D., Smith, C., Murphy, S. and Catford, J. 1993: Maintaining evaluation designs in long term community based health promotion programmes: Heartbeat Wales case study. Journal of Epidemiology and Community Health 47, 127-33.

ONS. 2005.

Partridge, C. and Johnston, M. 1989: Perceived control of recovery from physical disability: measurement and prediction. British Journal of Psychiatry 28, 53-59.

Paterson, B., Russell, C. and Thorne, S. 2000: Critical analysis of everyday self-care decision making in chronic illness. Journal of Advanced Nursing 35, 335-41. 
PAGB/WiPP. 2006: Self care aware: joining up self care in the NHS evaluation of the "Joining Up Self Care" Project in Erewash Primary Care Trust. London: WiPP/PAGB.

Potvin, L. and Richard, L. 2001: Evaluating community health promotion programmes. In Goodstadt, B., Rootman, I., Hyndman, D.V., McQueen, L. et al. editors, Evaluation in health promotion: principles and practices. Copenhagen: WHO Europe, 213-40.

Powell, D.R., Sharp, S.L., Farnell, S.D. and Smith, P.T. 1997: Implementing a self care program. Effect on employee health care utilization. AAOHN Journal 45, 247-53.

Rosenberg, M. 1989: Society and the adolescent self-image. Middletown CT: Wesleyan University Press.

Segall, A. and Goldstein, J. 1989: Exploring the correlates of self-provided health care behaviour. Social Science \& Medicine 29, 153-61.

Self Care Connect. 2009: Retrieved 6th January 2010 from www.selfcareconnect.co.uk.

Skills for Health. 2008: Common core principles to support self care. Bristol: Skills for Health.

South, J., Darby, F., Bagnall, A.M. and White, A. 2010: Implementing a community-based self care training initiative: a process evaluation. Health and Social Care in the Community 18, 662-70.

Steinweg, K.K., Killingsworth, R.E., Nannini, R.J. and Spayde, J. 1998: The impact on a health care system of a program to facilitate self-care. Military Medicine 63, 139-44.
Steptoe, A. and Ayers, S. 2004: Stress health and illness. In Sutton, S., Baum, A., Johnston, M., editors, The SAGE Handbook of Health Psychology. London: Sage, 169-96.

White, A. and Banks, I. 2009: Men and help seeking. In Kirby, R., Carson, C., White, A., Kirby, M., editors, Men's health, third edition. London: Informa Healthcare.

White, A., Bagnall, A.-M., South, J., Forshaw, M., Spoor, C., Witty, K. and Rooke, S. 2009a: An evaluation of the working in partnership programme self care in primary care initiative. Leeds: Metropolitan University. Available at http://www.leedsmet.ac.uk/hss/docs/Final_Report_SCin PC.pdf

White, A., South, J., Bagnall, A.-M., Forshaw, M., Spoor, C., Marchant, P., Jackson, K., Witty, K., and Rooke, S. 2009b: An evaluation of the working in partnership programme self care for people initiative. Leeds: Metropolitan University. Available at http://www.leedsmet.ac.uk/hss/docs/Final_report_ SC4P.pdf

Working in Partnership Programme (WiPP). 2006: WiPP self care skills training course: participants handbook. London. www.wipp.nhs.uk/self-care-for-people-tools

World Health Organisation (WHO). 1983: Health education in self-care: possibilities and limitations. Geneva: World Health Organisation.

Zigmond, A.S. and Snaith, R.P. 1983: The HAD scale. Acta Physiologica Scandinavica 67, 361-70. 